\title{
Sistem Informasi Reservasi Hotel Pada GM. Marsaringar Balige Berbasis Android
}

\author{
1)S. Artaulina Sitorus \\ UNIKA Santo Thomas Medan, JI. Setiabudi No. 479 F, Sumatera Utara, Indonesia \\ http:// www.ust.ac.id, Email : panesitorus@yahoo.com \\ ${ }^{2)}$ Emerson P. Malau \\ UNIKA Santo Thomas Medan, JI. Setiabudi No. 479 F, Sumatera Utara, Indonesia \\ http:// www.ust.ac.id, Email : malauemerson@gmail.com
}

\begin{abstract}
GM Hotels. Marsaringar Balige is a company engaged in hospitality services. During this time the reservation system at GM Hotels. Marsaringar Balige is still manual, such as booking rooms, recording guest data, and data from each part not yet integrated such as restaurant data, ballroom, karaoke, and making reports still using Microsoft Excel office applications. One effort to improve the quality of hospitality services at GMs. Marsaringar Balige is by utilizing information technology, namely by designing an Android-based Hotel Reservation Information System. Is the right solution to overcome the problems of hotel managerial data processing needs that are dynamic and can be accessed through websites or mobile devices. Mobile devices integrated with the web are one of the right choices for processing hotel information systems. A user / guest can get information by making a request from an application that was previously installed on an android smartphone to the database. All data exchange processes are stored on the web server. And the HotelGM Reservation Information System. Android-based Marsaringar Balige is built using the PHP programming language, Eclipse is supporting software for Android mobile, and Phpmyadmin as a tool for managing Mysql database, and Text editor using Macromedia Dreamweaver8.
\end{abstract}

Keywords: Information Systems, Hotel Reservations, PHP, Android

\section{PENDAHULUAN}

Perkembangan teknologi informasi saat ini sangat pesat dan telah mempengaruhi segala aspek bidang kehidupan manusia. Salah satunya dibidang jasa perhotelan, perkembangan teknologi informasi tersebut didukung oleh banyaknya perangkat lunak (software) dan perangkat keras (hardware) yang semakin hari semakin canggih diciptakan untuk memenuhi tuntutan kebutuhan yang dihadapi oleh manusia.Salah satu piranti teknologi adalah internet.dengan penemuan dan pengembangan ilmu pengetahuan dalam bidang informasi dan komunikasi, maka kemudahan penggunaan internet yang kini semakin banyak memberi tawaran pilihan aplikasi bagi para pengguna (user) dalam bentuk teknologi telepon cerdas (smartphone) yang seakan menghadirkan komputer dalam genggaman tangan ${ }^{[1]}$.

Smartphone adalah barang atau produk elektronik yang sedang berkembang saat ini, banyak masyarakat yang menggunakan smartphone untuk kebutuhan sehari-hari karena memiliki beragam fitur, dan smartphone merupakan komputer mini. Beberapa sistem operasi yang mendukung smartphone yaitu windows mobile, blackberry, symbian, iphone, dan android. Android adalah sebuah sistem operasi untuk perangkat mobile berbasis linux yang mencakup sistem operasi, middleware, dan aplikasi ${ }^{[3]}$.

Hotel merupakan fasilitas yang sudah menjadi kebutuhan penting bagi masyarakat dalam kebutuhan traveling, urusan bisnis, maupun wisata. Kabupaten Toba Samosir merupakan salah satu kawasan objek wisata.Sehingga bisnis perhotelan sangat banyak dijumpai pada kota balige, maka setiap para pemilik hotel semakin bersaing dalam memberikan layanan terbaik dari hotelnya. Demikian juga usaha yang dilakukan pada Hotel GM. Marsaringar Balige adalah dengan memberikan serta meningkatkan mutu pelayanan kepada tamunya.

Hotel GM. Marsaringar Balige merupakan salah satu perusahaan yang bergerak pada bidang pelayanan jasa perhotelan. Hotel ini berada di bawah naungan Dinas Pariwisata dan Kebudayaan Pemerintah Kabupaten Toba Samosir. Dan merupakan salah satu hotel yang sedang berkembang, dan terus berupaya untuk meningkatkan pelayanan serta standar kualitas hotelnya. Saat ini sistem reservasi pada Hotel GM. MarsaringarBalige masih manual, seperti 
pemesanan kamar kebanyakan menggunakan fasilitas telepon, serta datang langsung ke hotel, pencatatan data tamu menggunakan buku receptionist, dan untuk media promosi dalam bentuk brosur, proses check-in dan check-out serta laporan yang dihasilkan masih menggunakan Microsoft Office Excel, dan data dari setiap bagian belum terintegrasi satu sama lain seperti data restoran, ballroom, karaoke. Sehingga sistem tersebut perlu dibenahi.

Beberapa sistem yang perlu dibenahi adalah sistem pemesanan kamar hotel, proses check-in dan check-out, proses transaksi pembayaran, pengolahan data dari setiap bagian hotel, restoran, ballroom, karaoke yang dapat terintegrasi, juga dapat dilihat atau dimanipulasi sewaktu-waktu, dan pembuatan laporan yang efektif dan efisien, dengan memanfaatkan teknologi informasi. maka dengan sistem yang baru, yaitu Sistem Informasi Reservasi Hotel Pada GM. Marsaringar Balige Berbasis Android, merupakan solusi tepat untuk mengatasi permasalahan kebutuhan pengolahan data manajerial hotel yang bersifat dinamis dan dapat diakses melalui website maupun mobile. Perangkat mobile yang terintegrasi dengan web merupakan salah satu pilihan yang tepat untuk mengolah sistem informasi perhotelan pada GM. Marsaringar Balige. Dan user/tamu dapat memperoleh informasi hotel secara cepat dan akurat melalui website maupun mobile, dengan membuat permintaan dari aplikasi yang telah terpasang sebelumnya pada smartphone android ke database. Segala proses pertukaran data disimpan pada server web [8].

\section{METODE PENELITIAN}

\subsection{Perancangan Sistem}

Perancangan Sistem Informasi Reservasi Hotel GM Marsaringar Balige Berbasis Android ini akan menyajikan banyak fitur seperti pemesanan kamar secara online baik dari website ataupun dari mobile, dan setiap resepsionis hotel akan memproses data cekin dan cekout secara online. Maka pada dasarnya sistem ini akan mengerjakan pekerjaan tersebut secara otomatis.

\subsection{UML (Unified Modeling Language)}

UML merupakan alat komunikasi yang konsisten dalam mensuport para pengembang sistem saat ini. UML diaplikasikan untuk maksud tertentu ${ }^{[9]}$, biasanya antara lain untuk:
1. Merancang perangkat lunak

2. Sarana komunikasi antara perangkat lunak dengan proses bisnis

3. Menjabarkan sistem secara rinci untuk analisa dan mencari apa yang diperlukan sistem.

4. Mendokumentasi sistem yang ada, proses-proses dan organisasinya.

UML pada Sistem Informasi Reservasi Hotel GM Marsaringar Balige Berbasis Android dibedakan menjadi empat bagian, dijabarkan sebagai berikut:

Use Case menggambarkan external view dari sistem yang akan kita buat modelnya. Komponen pembentuk diagram use case adalah:

a. Aktor, menggambarkan pihak-pihak yang berperan dalam sistem.

b. Use case, aktivitas yang disiapkan oleh bisnis/sistem

c. Hubungan (link), aktor mana saja yang terlibat dalam use case ini

Use Case pada Sistem Informasi Reservasi Hotel GM Marsaringar Balige yang dibangun dapat dilihat seperti pada Gambar 1 berikut:

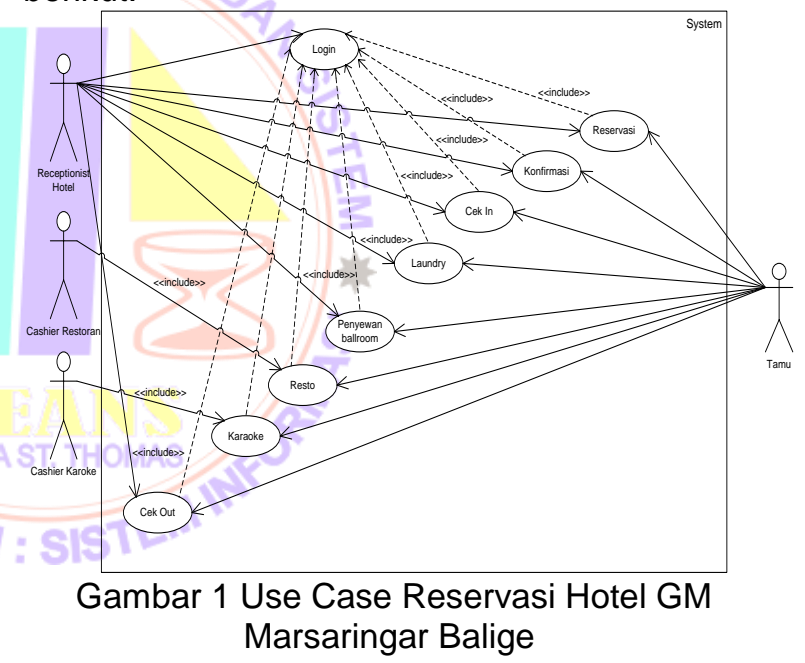

Pemodelan data digambarkan dalam bentuk Class Diagram yang menjelaskan visualisasi dari struktur kelas-kelas yang nantinya akan digunakan sebagai panduan pada tahap implementasi perangkat lunak. Karena perangkat lunak yang dirancang menggunakan PHP sebagai bahasa pemrogramannya, maka pemodelan data ini sangat berguna sekali terutama untuk melihat bagaimana perangkat lunak itu berjalan. Class Diagram pada sistem yang akan dibangun dapat dilihat seperti pada Gambar 2 berikut: 


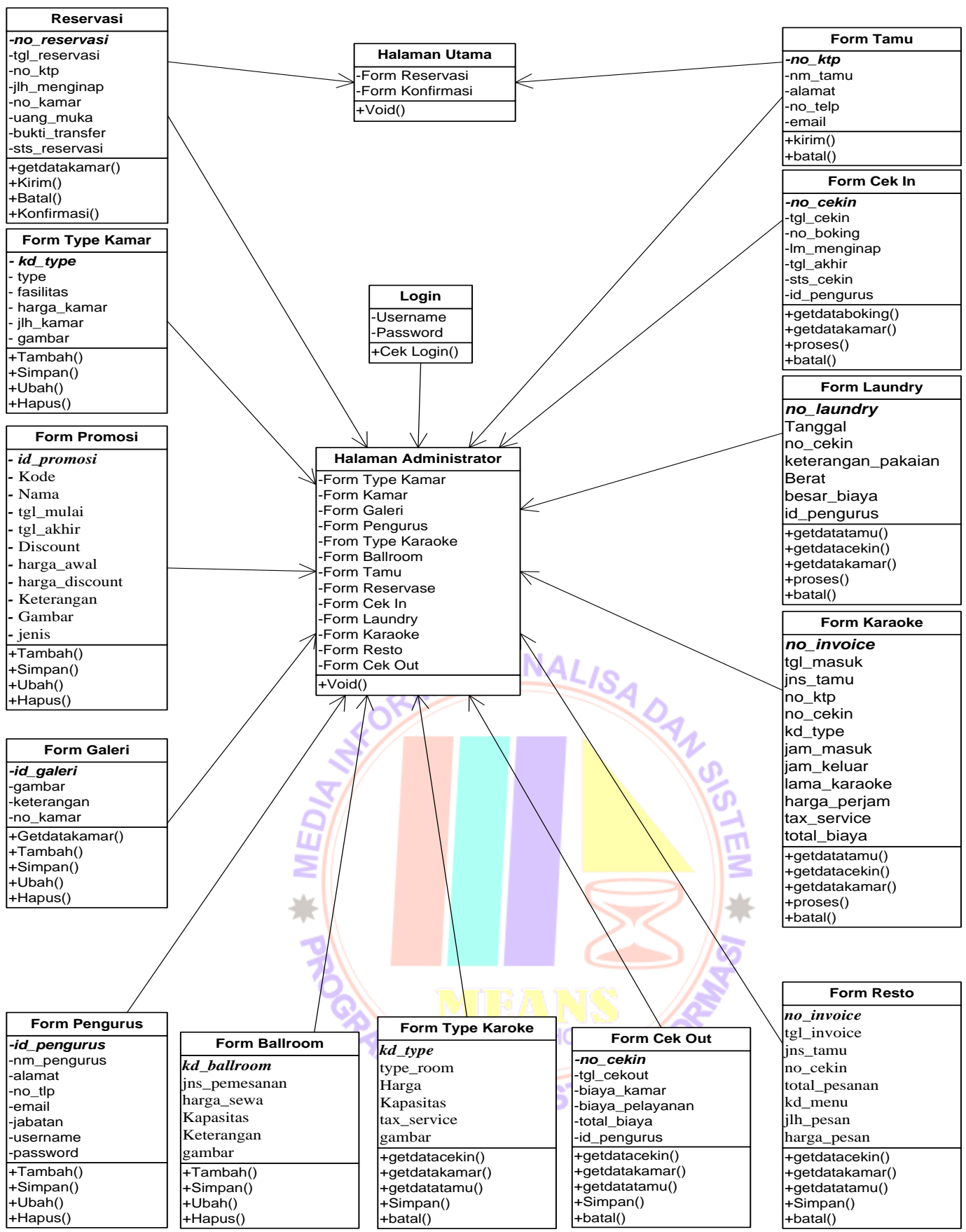

Gambar 2 Class Diagram

\section{HASIL DAN PEMBAHASAN}

\subsection{Implementasi Sistem}

Implementasi merupakan tahap pengenalan tentang bagaimana cara menjalankan sistem yang sudah dibangun. Pada bab ini akan dijelaskan langkah-langkah bagaimana cara menjalankan sistem. Pada sistem yang dibangun diimplementasikan dalam dua bentuk, yaitu sistem berbasis web dan sistem berbasis android. Berikut hasil implementasi dari sistem yang sudah dibangun adalah:

\section{a. Implementasi Pada Sistem Berbasis Android}

Halaman utama merupakan tampilan awal pada saat aplikasi dijalankan di smartphone android. Pada halaman utama terdapat informasi tentang hotel marsaringar seperti halaman kamar, restoran, karaoke, ballroom, cara reservasi dan promo hotel. Tampilan halaman utama dapat dilihat seperti pada Gambar 3. 


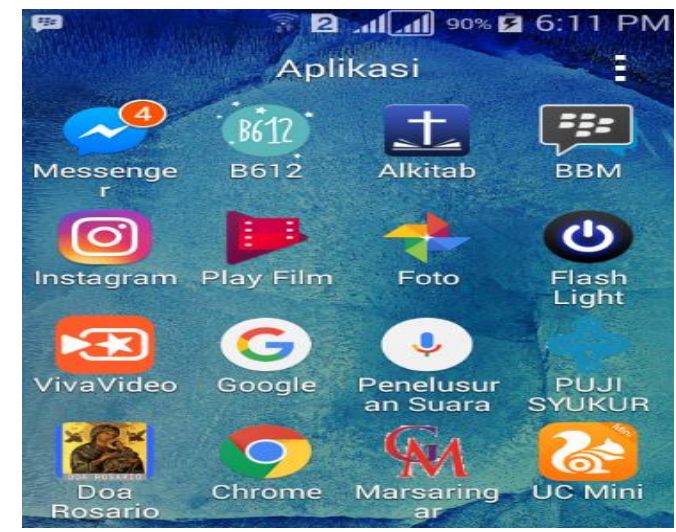

Gambar 3 Tampilan Splash Screen Aplikasi Hotel GM. Marsaringar

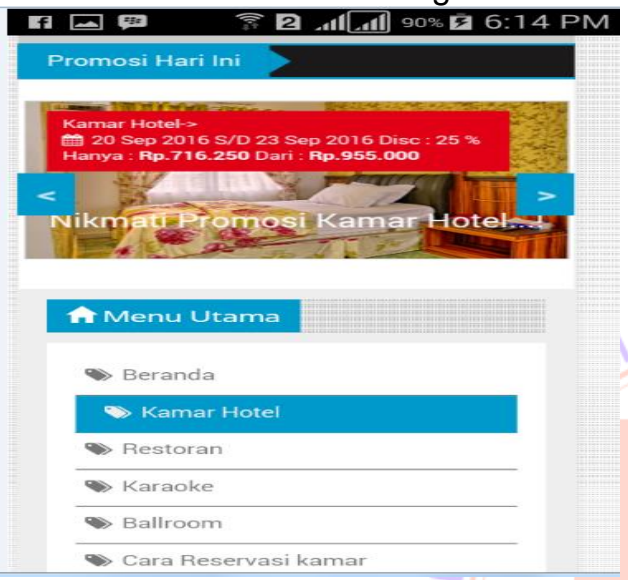

Gambar 4 Halaman Utama Aplikasi Hotel Marsaringar

Halaman tentang kami akan menampilkan informasi tentang Hotel GM. Marsaringar Balige. Dimana pada halaman ini akan ditampilkan informasi tentang sejarah, visi dan misi serta struktur organisasi Hotel Marsaringar Balige. Halaman tentang kami dapat dilihat seperti pada Gambar 5.

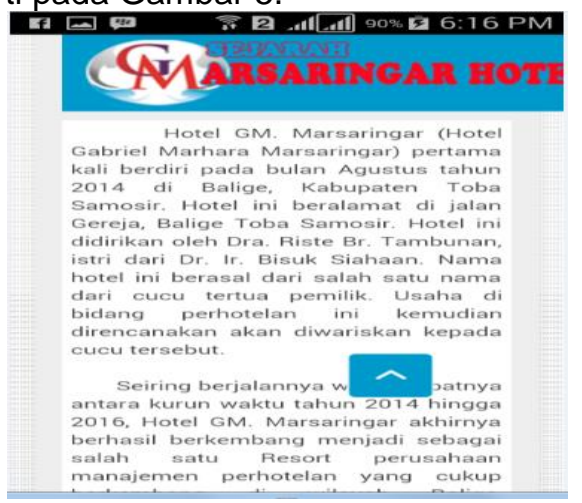

.Gambar 5 Tampilan Halaman Tentang Kami

Halaman hubungi kami akan menampilkan informasi tentang alamat Hotel GM. Marsaringar Balige dan nomor telepon yang dapat digunakan untuk menghubungi pihak Hotel Marsaringar Balige. Tampilan Halaman hubungi kami dapat dilihat seperti gambar 6 .

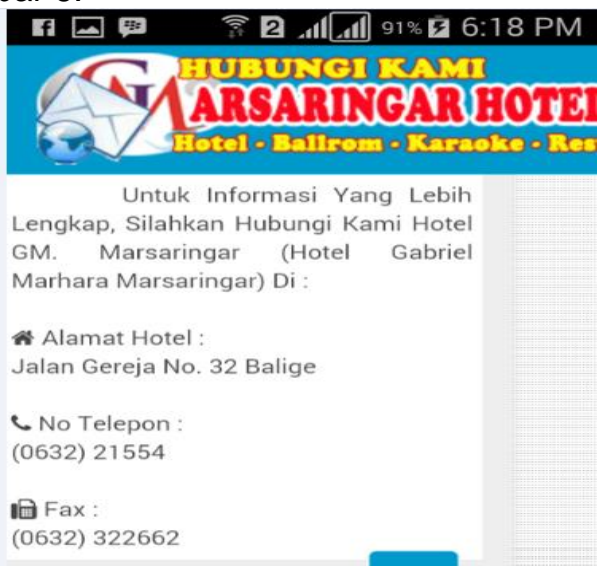

Gambar 6 Halaman Hubungi Kami

Pada halaman ini berfungsi untuk menampilkan informasi letak geografis hotel GM. marsaringar, Tampilan peta GM. Marsaringar Balige dapat dilihat seperti gambar 7.

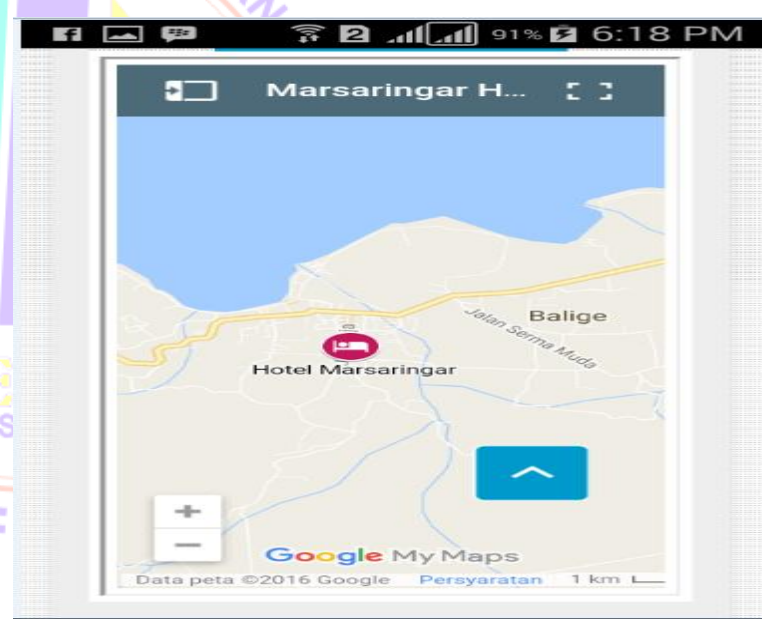

Gambar 7 Tampilan Peta atau Maps Hotel GM. Marsaringar

Halaman kamar hotel akan menampilkan informasi daftar type kamar hotel yang dapat dipesan oleh setiap pengunjung yang ingin menginap dari aplikasi mobile. Dimana pada halaman ini juga ditampilkan informasi biaya kamar. Halaman kamar hotel dapat dilihat seperti pada Gambar 8. 


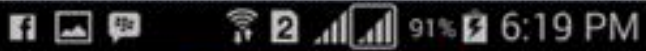

\section{Kamar Hotel}

2. Exablive Salt Rusm

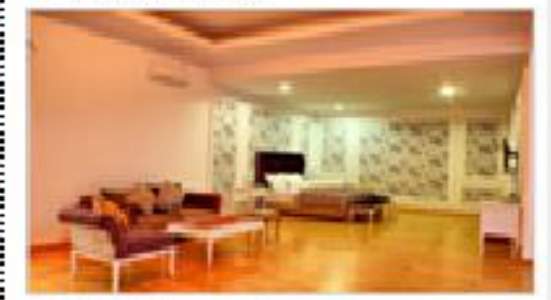

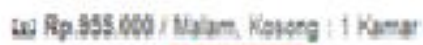

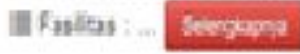

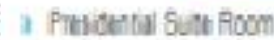

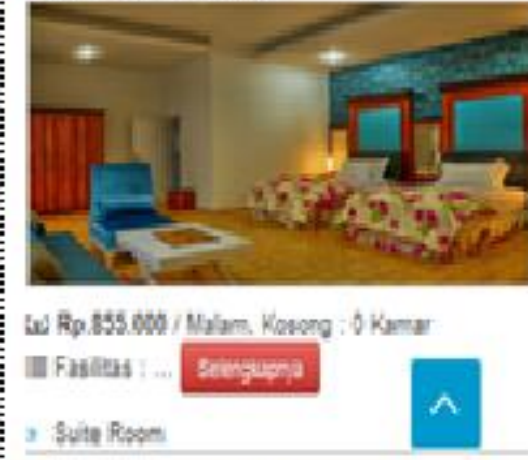

Gambar 8 Tampilan Halaman Kamar Hotel

Halaman detail kamar hotel akan menampilkan informasi lengkap kamar hotel seperti harga kamar, type kamar, dan fasilitas kamar, yang dapat dipilih dan dipesan oleh pengunjung yang ingin menginap, pada aplikasi android mobile. Halaman detail kamar hote dapat dilihat seperti pada Gambar 9 .

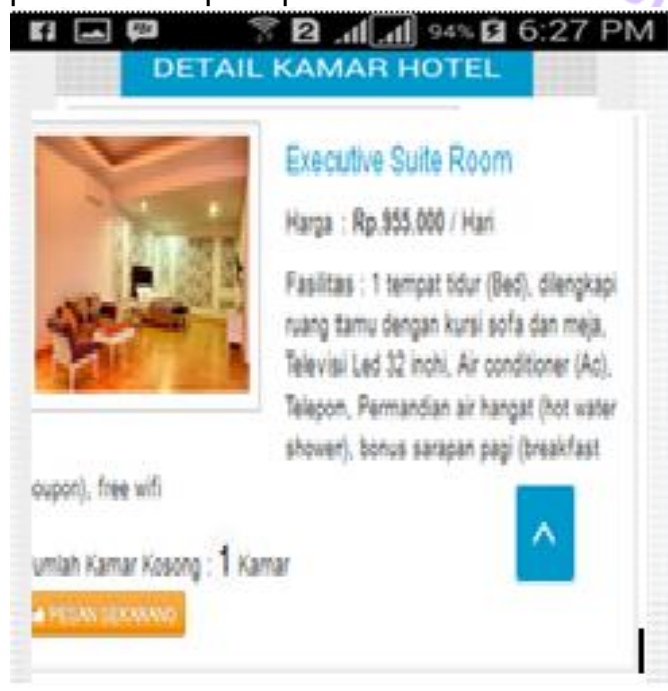

Gambar 9 Tampilan Halaman Detail Kamar Hotel
Halaman restoran akan menampilkan informasi lengkap tentang menu-menu yang disediakan di restoran hotel marsaringar balige. Halaman restoran dapat dilihat seperti pada Gambar 10.

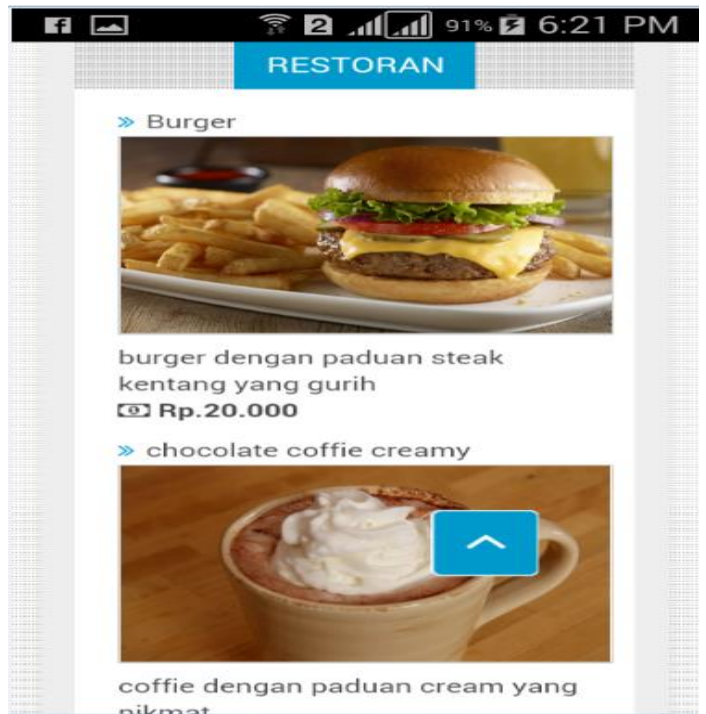

Gambar 10 Tampilan Halaman Restoran

Halaman karoke akan menampilkan informasi lengkap tentang karaoke seperti harga per jam sesuai type karaoke, kapasitas room karaoke, yang disediakan di hotel marsaringar balige. Halaman karaoke dapat dilihat seperti pada Gambar 11.

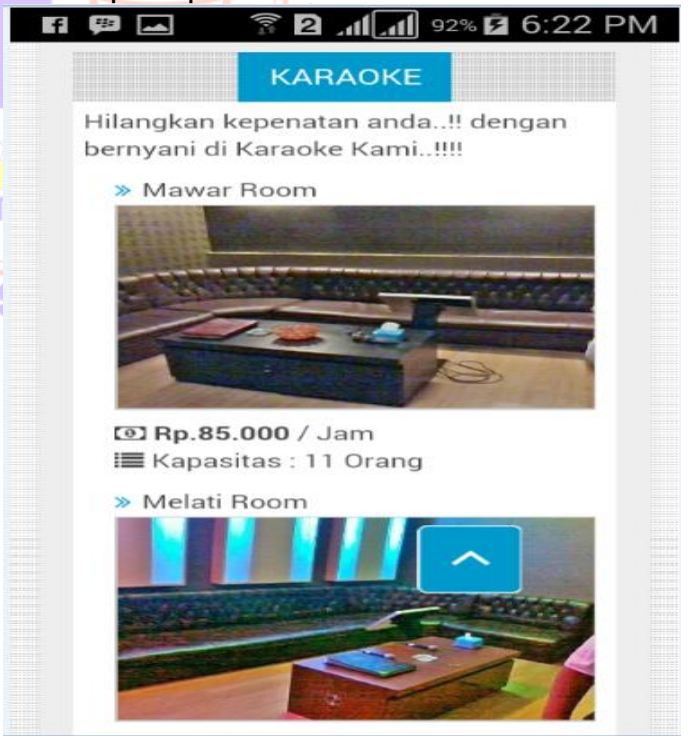

Gambar 11 Tampilan Halaman Karaoke

\section{KESIMPULAN}

Dengan selesainya tugas akhir ini yang berjudul Sistem Informasi Reservasi Hotel Pada GM. Marsaringar Balige Berbasis Android, mulai dari analisis sistem, perancangan sistem, sampai 
diuji program, maka penulis mengambil beberapa kesimpulan adalah sebagai berikut:

1. Dengan adanya aplikasi ini dapat membantu pengunjung atau tamu untuk mengetahui letak geografis lokasi hotel GM. Marsaringar Balige dengan mudah dan cepat dengan adanya fitur Google Maps.

2. Dengan adanya aplikasi ini, para pengunjung/tamu dapat melihat gallery kamar hotel, dan fasilitas pendukung pada hotel GM. Marsaringar Balige dan juga dapat memesan kamar secara online baik dari website maupun dari perangkat mobile

3. Dengan adanya media penyimpanan data (database), maka data dari tiap bagian seperti hotel, restoran,ballroom, karaoke,dapat terintegrasi. Makadapat membantu setiap pengurus hotel dalam mengolah data transaksi hotel. Dan pemilik hotel dapat melihat perkembangan hotel melalui laporan setiap transaksi per periode.

\section{DAFTAR PUSTAKA}

1. Fathansyah, 2012, Basis Data, Penerbit Informatika, Bandung

2. Hartono Jogiyanto, 2005, Pengenalan Komputer, Penerbit Andi, Yogyakarta

3. Irawan, 2012, Membuat Aplikasi Android Untuk Orang Awam, Penerbit Maxikom, Jakarta

4. Kadir, A, 2014, Pengenalan Sistem Informasi Edisi Revisi, Penerbit Andi, Yogyakarta

5. Prasetio Adhi, 2012, Buku Pintar Pemrograman Web, Penerbit Mediakita, Jakarta

6. Raharjo Budi, 2011, Belajar Pemrograman Web, Penerbit Modula, Bandung

7. Objek, Penerbit Informatika, Bandung

8. Safaat H. Nasruddin, 2012, Android Pemrograman Aplikasi Mobile Smartphone Dan Tablet Pc Berbasis Android, Penerbit Informatika,Bandung

9. Widodo P. P, dan Herlawati, 2011, Menggunakan UML, Penerbit Informatika, Bandung

10. http://journal.uny.ac.id/index.php/saintek/ar ticle/viewFile/9598/7663, (Diakses pada 13 September 2016)

11. http://ijns.org/journal/index.php/speed/articl e/viewFile/1295/1283, (Diakses pada 14 September 2016) 